\title{
ABSOLUTE CONFIGURATION OF 13-EPIMULINOLIC ACID
}

\author{
IVÁN BRITO* ${ }^{*}$ JORGE BORQUEZ ${ }^{1}$, ALEJANDRO CÁRDENAS ${ }^{2}$, MARIA AVENDAÑO ${ }^{\prime}$, \\ MARIO SIMIRGIOTIS
}

\author{
${ }^{1}$ Departamento de Química, Facultad de Ciencias Básicas, Universidad de Antofagasta, Casilla 170, Antofagasta, 1240000, Chile \\ ${ }^{2}$ Departamento de Física, Facultad de Ciencias Básicas, Universidad de Antofagasta, Casilla 170, Antofagasta, 1240000, Chile, \\ ${ }^{3}$ Instituto de Farmacia, Facultad de Ciencias, Universidad Austral de Chile, casilla 567, Valdivia 5090000, Chile.
}

\begin{abstract}
The molecular structure of the title compound [iupac name: 13-epi-8-hydroxy-3-isopropyl-5a,8-dimethyl-2,3,4,5,5a,6,7,8,10a,10b-decahydrocyclohepta[e] indene-3a $(1 \mathrm{H})$ acid] is similar to the structure of the known compound mulinolic acid.The structure of this mulinolic acid epimer consists of a mulinane skeleton and the isopropyl, methyl group, carboxylic acid and the hydroxyl group at $\mathrm{C} 3, \mathrm{C} 8, \mathrm{C} 5, \mathrm{C} 13$, respectively, which are $\beta$-oriented, whereas the methyl group at $\mathrm{C} 13$ are $\alpha$-oriented. The cyclopentane (A), ciclohexane (B) and cicloheptene (C) rings are trans (A/B) and (B/C) cis fused, and are in an envelope, chair, and twist chair conformation respectively. In the crystal the molecules are linked by two strong intermolecular $\mathrm{O}-\mathrm{H} \cdots \mathrm{O}$ hydrogen bond forming bidimensional supramolecular structures with graph-set notation (12) and (46). The absolute configuration of the title compound which has been determined from the refinement of the Flack parameter $^{16}$. On this basis the absolute configuration was assigned as C3R, C5S, C8S, C9S,C10S and C13S.
\end{abstract}

Keywords: Absolute configuration, Diterpenoid, X-ray diffraction, Crystal and Supramolecular structure.

\section{INTRODUCTION}

In the course of studies on diterpenoids from species of the tribe Mulinae (Umbelliferae), we have reported on the structures of several mulinane derivatives obtained from the petrol extracts of Laretia acaulis (Cav.) Gill et Hook., Mulinum crassifolium and Azorella compacta Phil ${ }^{1-5}$. In the continuation of our phytochemical investigation of Umbelliferae we have study again Laretia acaulis (Cav.) Gill et Hook., known in Chile as "llareta de la zona central". This plant is a yellowish-green, compact resinous cushion shrub, which grows in the Andes of Chile. Whole plant infusions plan are widely used as diabetes treatment in folk medicine ${ }^{6}$. The relative stereochemistry of 13-epimulinolic acid was assigned on the careful spectroscopic comparison with mulinolic acid and by chemical transformation ${ }^{5}$. In this paper we report the absolute configuration of the title compound which has been determined from the refinement of the Flack parameter ${ }^{16}, x=-0.01(12)$, indicated that correct configuration had been assigned against $1220, \mathrm{CuK} \alpha$ Bijvoet pairs. On this basis the absolute configuration was assigned as: C3R, C5S, C8S, C9S,C10S and C13S.

\section{EXPERIMENTAL}

The title compound $\mathrm{C}_{20} \mathrm{H}_{32} \mathrm{O}_{3}$ was isolated using medium pressure column chromatography (MPCC). In a continuation of our program for the chemical study of the Atacama Desert Flora ${ }^{7-10}$, dried aerial parts of Laretia acaulis (1130 g) collected in april 2014 in the pre-Andean mountain range of Atacama Desert, precordillera de la III Region, Northern Chile were extracted with n-hexane (3 liters, 3 times in the dark, $24 \mathrm{~h}$ each time) and $180 \mathrm{~g}$ of a yellow gum were obtained after evaporation of the solvent. A portion of the extract $(20.0 \mathrm{~g})$ was filtered and submitted to a medium pressure column chromatography system composed of an $2.5 \mathrm{~cm} \times 48 \mathrm{~cm}$ medium pressure column (Aceglass inc, Vineland, NY, USA) packed with silicagel (Kieselgel 60 H, Merck, Darmstadt, Germany) using an isocratic solvent system of $n$-hexane-ethyl acetate (9.5:0.5

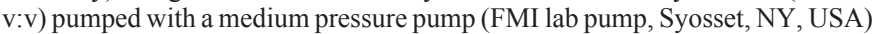
with a flow rate of $10 \mathrm{~mL}$-minute. The collected fractions $(75)$ were combined according to TLC analysis (Kieselgel F254 plates, developed with Hexane: EtOAc 8:2 v/v, and spots visualized by spraying with vanillin:sulfuric acid 2 $\%$ in ethanol and heating) and ten combined fractions were obtained. Fraction $2(350 \mathrm{mg})$ was re-chromatographed using the same chromatographic system and the known compounds: mulin-11, 13-dien-20-oic acid (40 mg), mulinolic $\operatorname{acid}^{5}$ and 13-epimulinolic $\operatorname{acid}^{6}(120 \mathrm{mg})$. Recrystallization de 13-epimulinolic acid from ethyl acetate a room temperature yielded white crystals, which were suitable for X-ray diffraction analysis.

13-epimulinolic acid, white crystals, m.p. $240-243{ }^{\circ} \mathrm{C}$. The molecular weight was determined by orbitrap ESI-MS/MS with a mass spectrometer (Q-exactive Focus, Bremen, Germany) [M-H] : 319.22752 calcd. for $\mathrm{C}_{20} \mathrm{H}_{31} \mathrm{O}_{3}{ }^{-}$: 319.22787. ${ }^{1} \mathrm{H}$ NMR (Bruker Avance $\left.300 \mathrm{MHz}^{\mathrm{CDCl}} \mathrm{CDC}_{3}\right) \delta \mathrm{ppm}: 0.80(3 \mathrm{H}, \mathrm{d}, \mathrm{J}$ $=5.8 \mathrm{~Hz}, \mathrm{Me}-18), 0.93(3 \mathrm{H}, \mathrm{s}, \mathrm{Me}-17), 0.97(3 \mathrm{H}, \mathrm{d}, \mathrm{J}=5.8 \mathrm{~Hz}, \mathrm{Me}-19), 1.07$
$(1 \mathrm{H}, \mathrm{dd}, \mathrm{J}=4.8,14.6 \mathrm{~Hz}, \mathrm{H}-15 \beta), 1.23(3 \mathrm{H}, \mathrm{s})$ 1.315.(3H, m, H-7 $\beta, \mathrm{H}-6 \alpha$,

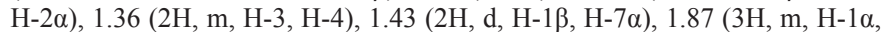
$\mathrm{H}-2 \beta, \mathrm{H}-10 \alpha), 1.51(1 \mathrm{H}, \mathrm{dd}, \mathrm{J}=5.9,13.5 \mathrm{~Hz}, \mathrm{H}-14 \beta), 2.00(1 \mathrm{H}, \mathrm{dd}, \mathrm{J}=13.5$, $14.6 \mathrm{~Hz}, \mathrm{H}-14 \alpha), 2.05(1 \mathrm{H}, \mathrm{dd}, \mathrm{J}=8.2,11.0 \mathrm{~Hz}, \mathrm{H}-9 \beta), 2.17(1 \mathrm{H}, \mathrm{t}, \mathrm{J}=2.17$ $\mathrm{Hz}), 2.35$ (1H, m, H-6ß), $5.26(1 \mathrm{H}, \mathrm{dd}, \mathrm{J}=8.2,12.9 \mathrm{~Hz}, \mathrm{H}-11), 5.48(1 \mathrm{H}, \mathrm{d}$, $\mathrm{H}-12) .{ }^{13} \mathrm{C}$ NMR $\left({ }^{13} \mathrm{C}\right.$ NMR Bruker Avance $\left.75 \mathrm{MHz}, \mathrm{CDCl}_{3}\right) \delta \mathrm{ppm}: 177.0$ $(\mathrm{COOH}), 138.1$ (C-11), 127.0 (C-12), 74.1 (C-13), 57.8 (C-5), 57.4 (C-3), 50.9 (C-10), 48.0 (C-9), 41.9 (C-7), 36.8 (C-14), 35.6 (C-8), 32.5 (C-6), 31.7 (C-4), 30.7 (C-15), 28.7 (C-2), 28.4 (Me-16), 27.5 (Me-17), 24.7 (C-1), 22.5 (Me-19), 22.1 (Me-18). These data, together with HR-MS data and correlations observed in the HSQC and HMBC spectra, are consistent with the structure of 13-epimulinolic acid(Fig. 1). The spectroscopic data showed resemblance with those similar mulinane structures reported in the literature ${ }^{10-12}$.

Data collection, structural determination and refinement was performed with a Bruker AXS D8-Venture, Triumph- $\mu \mathrm{I}-\mathrm{Cu}$ with graphite-monochromated $\mathrm{CuK} \alpha$ radiation $(1.54178 \AA$ ). The structure was solved by direct method, and was refined against $\mathrm{F}^{2}$ by full-matrix least-squares methods using SHELXL ${ }^{13}$. All of the non-hydrogen atoms were refined anisotropically. The hydrogen atoms was located from a difference Fourier map and allowed to ride on their parent $\mathrm{C}$ atoms, with isotropic displacement parameters related to the refined values of the corresponding parent atoms. $\mathrm{H}$ atoms bonded to $\mathrm{O}$ atoms were freely refined with isotropic displacement parameters. The final Fourier maps, the electron-density residuals were not significant. Crystallographic data, details of data collection and structure refinement parameters for the title compound is summarized in Table 1. Program used to solve structure: SHELXS-201313, program used to refine structure: SHELXL-201313, molecular graphics ${ }^{14}$. The absolute configuration of the title compound which has been determined from the refinement of the Flack parameter ${ }^{16}, x=-0.01(12)$, indicated that correct configuration had been assigned, against $1220, \mathrm{CuK} \alpha$ Bijvoet pairs.

\section{RESULTS AND DISCUSSION}

The molecular structure and the absolute configuration of the title compound was confirmed by $\mathrm{x}$-ray diffraction analysis of suitable single crystals (Fig.2). Colorless block crystals of title compound with approximate dimensions $0.250 \times 0.200 \times 0.200 \mathrm{~mm}$ was obtained by slow evaporation of a ethyl acetate solution. The molecular structure [iupac name:8 -hydroxy-3-isopropyl-5a, 8 dimetyl-2,3,4,5,5a,6,7,8,10a,10b-decahydrocyclohepta[e]indene-3a(1H) acid] consists of a mulinic acid skeleton and the isopropyl, methyl group, carboxylic acid and hydroxyl group at $\mathrm{C} 3, \mathrm{C} 8, \mathrm{C} 5, \mathrm{C} 13$ respectively, which are $\beta$-oriented, whereas the methyl group at $\mathrm{C} 13$ is $\alpha$-oriented, Fig.2 The Cremer and Pople parameters $^{15}$ for the cyclopentane (A), ciclohexane (B) and cicloheptene (C) rings are: $\mathrm{Q}_{2}=0.425(3) \AA, \varphi_{2}=112.2(4)^{\circ} ; \mathrm{Q}_{\mathrm{T}}=0.578(3) \AA, \theta=173.8(3)^{\circ}$, $\varphi=164(2)^{\circ}$ and $\mathrm{Q} 2=0.104(3) \AA, \varphi_{2}=106.7(15)^{\circ}, \mathrm{Q} 3=0.577(3), \varphi_{3}=333.9(3)^{\circ}$, so the conformation for $\mathrm{A}, \mathrm{B}$ and $\mathrm{C}$ rings are: envelope, chair, and twist chair respectively. The $\mathrm{A} / \mathrm{B}$ and $\mathrm{B} / \mathrm{C}$ rings are trans and cis fused respectively. The 
$\mathrm{OH}$ groups are involved in hydrogen bonding interactions with the average $\mathrm{H} \cdots \mathrm{O}$ distance of $1.895 \AA$ and $\mathrm{O}-\mathrm{H} \cdots \mathrm{O}$ angles of $171.5^{\circ}$, Table 2 , so in the crystal the molecules are linked by two strong intermolecular $\mathrm{O}-\mathrm{H} \cdots \mathrm{O}$ hydrogen bond forming bidimensional supramolecular structures with graphset notation (12) and (46) ${ }^{17}$, Fig.3 and Fig.4. All bond distances and angles are normal.

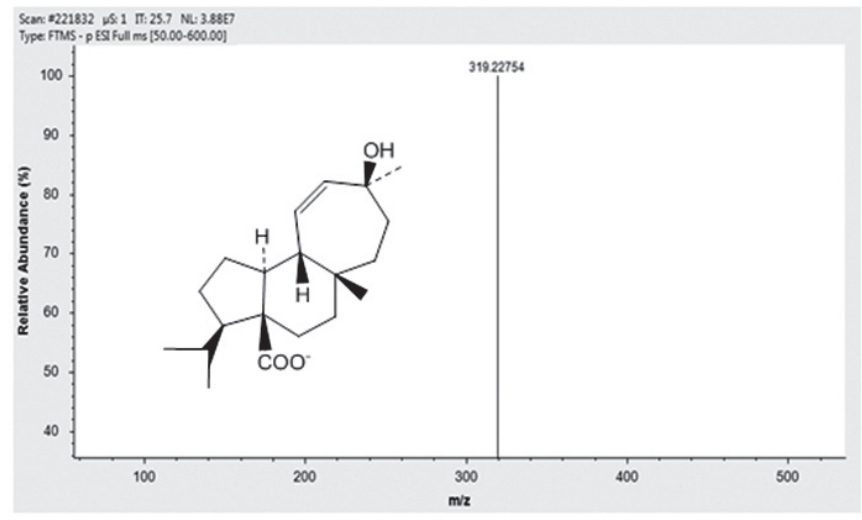

Fig. 1: Full Orbitrap HESI (-) spectra of compound 13-epimulinolic acid.

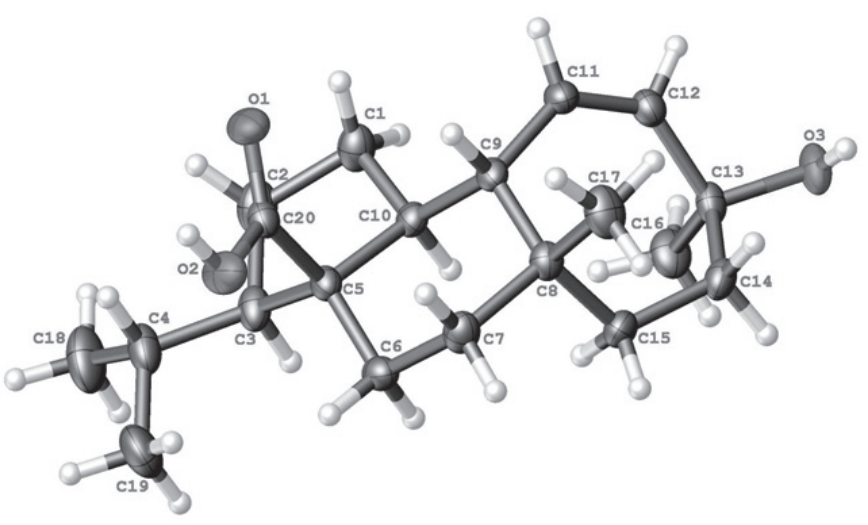

Fig.2: ORTEP Diagram of 13-epimulinolic acid. The ellipsoids are shown at the $30 \%$ probability level.

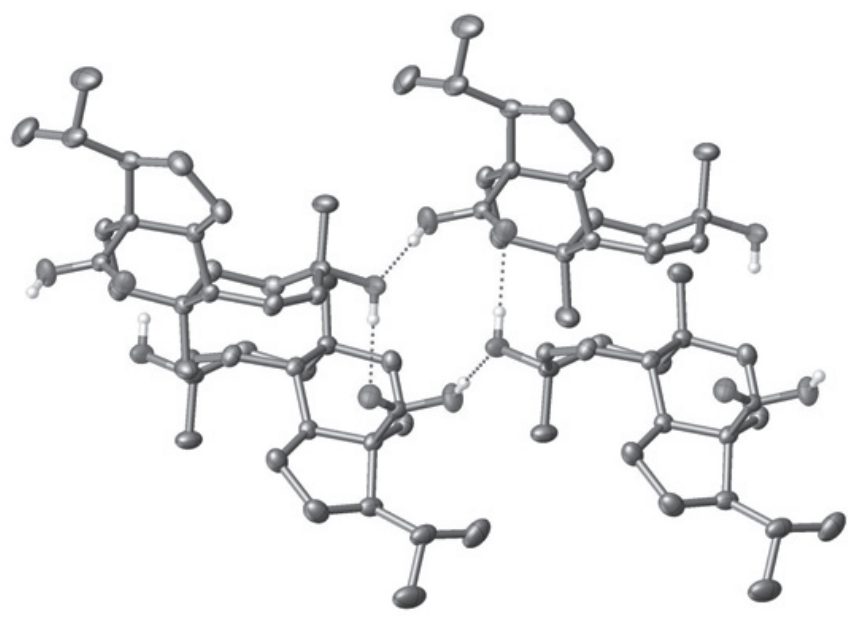

Fig.3 A view of the bi-dimensional supramolecular aggregate, showing the formation of ring with set-graph motif (12)

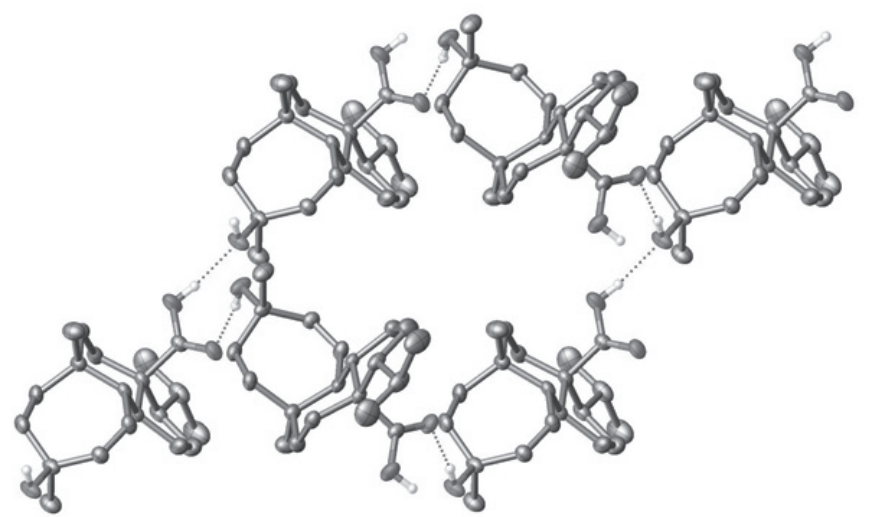

Fig.4 A view of the bi-dimensional supramolecular aggregate, showing the formation of ring with set-graph motif (46).

Table 1. Crystallographic data, details of data collection and structure refinement parameters for title compound

Crystal data

$\mathrm{C}_{20} \mathrm{H}_{32} \mathrm{O}_{3}$

$\mathrm{V}=3874.8(2) \AA^{3}$

$\mathrm{Mr}=320.45$

$\mathrm{Z}=8$

Orthorhombic, $\mathrm{C} 2221$

$\mathrm{CuK} \alpha(\lambda=1.54178 \AA)$

$\mathrm{a}=12.3345(4) \AA \quad \alpha=90^{\circ}$

$\mathrm{b}=17.2102(5) \AA \quad \beta=90^{\circ}$

$\mu=0.564 \mathrm{~mm}^{-1}$

$\mathrm{T}=296(2) \mathrm{K}$

$\mathrm{c}=18.2531(5) \AA \quad \gamma=90^{\circ}$

Colourless, Block, $0.25 \times 0.20 \times 0.20 \mathrm{~mm}$

Data Collection

Diffractometer Bruker AXS D8-Venture, Triumph-I $\mu-\mathrm{Cu}$

2793 reflections with $\mathrm{I}>2 \sigma(\mathrm{I})$

$\begin{array}{lc}14145 \text { measured reflections } & \mathrm{R}_{\mathrm{int}}=0.0568 \\ 2793 \text { independent reflections } & \\ 2 \theta \text { range for data collection } & 8.82 \text { to } 118.09^{\circ}\end{array}$

Index ranges

$-13 \leq \mathrm{h} \leq 13,-17 \leq \mathrm{k} \leq 19,-19 \leq 1 \leq 20$

Refinement
$\mathrm{R}\left[\mathrm{F}^{2}>2 \sigma\left(\mathrm{F}^{2}\right)\right]=0.0335$
$\mathrm{wR}\left[\mathrm{F}^{2}\right]=0.0818$

Flack parameter ${ }^{16}-0.01(12)$
215 parameters

$\mathrm{S}=1.052$

$\Delta \rho_{\max }=0.14 \mathrm{e} \cdot \AA^{-3}$

$\Delta \rho_{\min }=-0.12 \mathrm{e} \cdot \AA^{-3}$

Goodness-of-fit on $\mathrm{F}^{2} \quad 1.052$
Table 2: Hydrogen-bonding geometry $\left(\AA,^{\circ}\right)$

\begin{tabular}{|c|c|c|c|c|}
\hline $\mathrm{D}-\mathrm{H} \cdots \mathrm{A}$ & $\mathrm{D}-\mathrm{H}$ & $\mathrm{H} \cdots \mathrm{A}$ & $\mathrm{D} \cdots \mathrm{A}$ & $\mathrm{D}-\mathrm{H} \cdots \mathrm{A}$ \\
\hline $\mathrm{O} 3-\mathrm{H} 1 \cdots \mathrm{O} 1^{\mathrm{i}}$ & 0.82 & 1.98 & $2.794(2)$ & 171 \\
\hline $\mathrm{O} 2-\mathrm{H} 2 \cdots \mathrm{O} 3^{\mathrm{ii}}$ & 0.82 & 1.81 & $2.624(3)$ & 172 \\
\hline
\end{tabular}

symmetry code: (i) $-1 / 2+x, 3 / 2-y, 1-z$; (ii) $1 / 2+x,-1 / 2+y, z$

\section{CONCLUSIONS}

In order to establish its absolute configuration, a single-crystal X-ray diffraction analysis of 13-epimulinolic acid was undertaken. The X-ray molecular model of the title compound (Fig.2), confirmed all the above deductions on its structure and established the absolute configuration as $\mathrm{C} 3 \mathrm{R}$, C5S, C8S, C9S,C10S and C13S.

Supplementary material

CCDC- 1518397 contains the supplementary crystallographic data for 
this article. These data can be obtained free of charge from the Cambridge Crystallographic Data Centre via www.ccdc.cam.ac.uk/data request/cif.

\section{ACKNOWLEDGEMENTS}

IB acknowledgment Fondequip Program ( Grant EQM130021) for the funding to purchase Single Crystal X- ray Diffractometer. JB \& MS thanks FONDECYT (Chile) (Grant 1140178) and Fondequip (EQM140002) for financial support. We also thank CONAF (Corporación Nacional Forestal) Chile for the permission and support in the collection of the flora of protected areas of northern Chile.

\section{REFERENCES}

1. L. A. Loyola, J. Bórquez, G. Morales, A. San-Martín. Phytochemistry. 44, 649, (1997)

2. L. A. Loyola, J. Bórquez, G. Morales, A. San-Martín. Phytochemistry. 45, 1465, (1997).

3. L. A. Loyola, G. Morales, B. Rodríguez, J. Jiménez-Barbero, S. Pedreros, M. C. de la Torre, A. Perales, M. R. Torres. Tetrahedron. 46, 5413, (1990).

4. L. A. Loyola, G. Morales, B. Rodríguez, J. Jiménez-Barbero, S. Pedreros, M. C de la Torre, A. Perales. Journal of Natural Product. 54, 1404, (1991).

5. L. A. Loyola, J. Bórquez, G. Morales, A. San-Martín. Phytochemistry. 43, $165,(1996)$.
6. L. A. Loyola, J. Bórquez, G. Morales, A. San-Martín. Phytochemistry. 53, 961, (2000).

7. I.Brito, M.J.Simirgiotis, A.Brito, M.R.Werner, J. Bórquez, P. Winterhalter, A. Cárdenas. Journal of the Chilean Chemical Society 60, (1), 2864, (2015)

8. I. Brito, J. Bórquez, M. Simirgiotis, M. Neves-Vieira, G. Jerz, P. Winterhalter, M. Bolte, A. Cárdenas. Zeitschrift für Kristallographie-New Crystal Structures 229, 399, (2014)

9. J. Bórquez, A.Ardiles, L.A. Loyola, L.M. Peña-Rodriguez, G.M. MolinaSalinas, J. Vallejos, I.G.Collado, M.J. Simirgiotis. Molecules, 19, 3898 (2014)

10. J. Bórquez, N.L. Bartolucci, C. Echiburú-Chau, P. Winterhalter, J. Vallejos, G. Jerz, M.J. Simirgiotis. Journal of the Science of Food and Agriculture 96, (8), 2832, (2016)

11. J. Bórquez, N. L. Bartolucci, C. Echiburú-Chau, P. Winterhalter, J. Vallejos, G. Jerz, M. J. Simirgiotis. Journal of the Science of Food and Agriculture. 96, (8), 2832, (2016)

12. L. A. Loyola, J. Bórquez, G. Morales, A.San Martín. Phytochemistry. 4, (1), 165, (1996).

13. G. M. Sheldrick, Acta Cryst. 112, A64, (2008)

14. O.V. Dolomanov, L.J. Bourhis, R.J. Gildea, J.A.K. Howard, H. Puschmann, J. Appl. Cryst., 42, 339, (2009)

15. D.Cremer, J.A. Pople. J.Am.Chem.Soc. 97, 1354, (1975)

16. H.D. Flack. Acta Cryst. A39, 876, (1983)

17. J. Bernstein, R.E. Davis, L. Shimoni, N.-L. Chang. Angew. Chem. Int. Ed. Engl. 34, 1555, (1995) 